\title{
Crime ou desordem de acumulação de animais? O PaPel das Redes sociais no entendimento dos ACONTECIMENTOS DE SANTO TIRSO
}

\author{
Susana COSTA* \\ Catarina CASANOVA**
}

\begin{abstract}
RESUMO: Na madrugada de 19 de Julho (2020), em Santo Tirso (Portugal), um fogo florestal atingiu dois abrigos ilegais para animais de companhia. Meia centena morreu. Foram resgatados com vida 110 não-humanos. As informações veículadas pelos media indicam a possibilidade de estarmos perante um caso de acumulação de animais. Tendo por base as publicações de Facebook relacionadas com o incidente de duas das maiores organizações portuguesas defensoras da causa animal, procurámos perceber como é que as mesmas e os seus seguidores reagiram ao acontecimento. A análise foi feita com base na técnica de análise de contéudo. Os resultados sugerem que tanto as organizações em causa como os seus seguidores percepcionaram o acontecimento como um acto criminoso. Apesar das informações disponíveis, a possibilidade de estarmos perante a "desordem de acumulação de animais" nunca foi mencionada nas publicações dos murais analisados e surge apenas uma vez no comentário de um dos seus seguidores.
\end{abstract}

PALAVRAS-CHAVE: Desordem de acumulação de animais. Santo Tirso. Análise de contéudo. Redes sociais. Direitos dos animais.

Introdução

Na madrugada de 19 de Julho de 2020 dois abrigos para animais de companhia,

\footnotetext{
* UC - Universidade de Coimbra. CIAS - Centro de Investigação em Antropologia e Saúde. Departamento de Ciências da Vida. Coimbra - Portugal. 3000-456 - susanagkosta@gmail.com. https://orcid.org/00000002-2766-0135.

** UC - University of Coimbra. Research Centre for Anthropology and Health. Department of Life Sciences. Coimbra - Portugal. 3000-456 - ccasanova@iscsp.ulisboa.pt. https://orcid.org/0000-0003-2123-0262.
} 
localizados no concelho de Santo Tirso (Porto, Portugal), foram atingidos por um fogo florestal. Ambos, localizados em propriedade privada, pertenciam a duas mulheres mãe e filha - que, de acordo com a comunicação social, terão solicitado às autoridades para que não deixassem entrar os populares e os voluntários que se foram acumulando nas imediações na esperança de resgatarem os animais que ali se encontravam retidos. A ajuda tardia foi alegadamente responsável pela morte de 52 cães e de 2 gatos (números apurados no local). Provavelmente o facto dos populares e voluntários de organizações ligados à causa animal se terem visto impedidos de entrar nas propriedades em causa, também contribuiu para este desfecho. Cento e dez animais foram resgatados com vida, embora a maioria tenha necessitado de assistência médica. Desconhece-se actualmente se, entretando, ocorreram mais óbitos.

Os abrigos em causa - Cantinho das 4 Patas e Abrigo de Paredes - situavam-se numa área florestal, longe dos olhares da maioria da população e eram sustentados por donativos particulares e de outras instituições zoófilas. A falta de condições de ambos já tinha sido anteriormente relatada e dada a conhecer à Câmara Municipal de Santo Tirso pelo veterinário municipal. Em 2017, foi apresentada uma queixa no Ministério Público por alegados maus-tratos e negligência nestes locais. O tribunal arquivou a queixa tempos depois por considerar que: "apesar de não prestar as ideais condições aos animais que ali estão acolhidos, pois poderia e deveria estar mais limpo, não existe crueldade em manter animais num espaço sujo, com lixo, dejetos e mau cheiro" (PEREIRA, 2020,n.p.).

$\mathrm{Na}$ sequência da morte destes animais, a onda de indignação que assolou todo o país não se fez esperar e atingiu várias esferas e instituições nacionais (Câmara Municipal de Santo Tirso, Guarda Nacional Republicana, Autoridade Nacional de Emergência e Protecção Civil, Ministério da Administração Interna, Ordem dos Médicos Veterinários, Direcção Geral de Alimentação e Veterinária (DGAV), Assembleia da República, entre outros). Tal foi a onda de protestos dos cidadãos que o próprio Primeiro Ministro se viu obrigado a vir a público lamentar a morte dos animais em questão.

Não sendo o nosso propósito criar uma cronologia de acontecimentos e de efeitos colaterais, a verdade é que entre inquéritos e outros procedimentos disciplinares e judiciais instaurados pelas entidades competentes, o efeito maior dos acontecimentos verificou-se na opinião pública que nos tempos actuais encontra terreno especialmente fértil na redes sociais para se expressar.

É com base nas mesmas que o presente artigo se desenrolará. O nosso objectivo é, recorrendo à etnografia digital através das publicações de organizações ligadas à causa animal, perceber em que moldes essas mesmas organizações e os seus seguidores 
percepcionaram o acontecimento.

\section{Breve análise da anatomia do acontecimento}

Para se entender por completo o contexto em que o acontecimento em causa ocorreu, é necessário analisar por partes as instituições, os humanos envolvidos e o modo como estes percepcionam os não-humanos cativos nos locais em causa.

\section{A DGAV e os médicos veterinários municipais}

Começamos por analisar a posição e as competências da DGAV que, à época, era o organismo responsável pelos assuntos relacionados com os animais de companhia em território português e - consequentemente - pelos médicos veterinários municipais ${ }^{1}$.

No seu site oficial, a DGAV define assim a sua missão:

“A DGAV é um serviço central da administração direta do Estado, dotado de autonomia administrativa e integrado no Ministério que tutela o setor agro pecuário. As suas competências respeitam à saúde e proteção animal; regulamentação e coordenação do controlo alimentar; e sanidade vegetal e fitossanidade.”(DGAV, 2020, n.p.).

No que à protecção animal diz respeito, a DGAV acrescenta actuar nos seguintes âmbitos: animais com interesse pecuário, animais em transporte, animais no abate, animais de companhia, animais em parques zoológicos e animais para fins científicos. No que aos animais de companhia em concreto diz respeito, este organismo estatal diz:

Qualquer detentor particular, mesmo que apenas detenha animais de companhia sem quaisquer fins lucrativos, num apartamento, numa vivenda ou num terreno da sua propriedade, deve ter em atenção o cumprimento de requisitos mínimos (espaço adequado que permita a prática de exercício e a fuga e refúgio dos animais, a proteção contra o sol, a chuva e o vento, ventilação, temperatura e

\footnotetext{
${ }^{1}$ A DGAV estava, na altura dos acontecimentos, sob a tutela do Ministério da Agricultura. Na sequência dos eventos aqui relatados e portanto como consequência política, os assuntos relacionados com os animais de companhia passaram - poucos dias depois - a estar sob a tutela do Ministério do Ambiente.
} 
condições de luminosidade adequadas à espécie, acesso a água e a comida adequadas à espécie e à idade). [...]. Tanto os locais onde os animais são alojados, como os comedouros e os bebedouros, devem ser mantidos em boas condições de higiene. (DGAV, 2020, n.p.).

Fica evidente que o organismo em causa tem uma actuação vasta, não havendo grande margem para se dedicar em concreto aos assuntos ligados aos animais de companhia. De todas as suas competências, apenas uma é concretamente ligada a estes, sendo todas as outras associadas aos denominados animais de produção e de laboratório. Assim, actividades que visam a fiscalização das condições sanitárias e promotoras do bem-estar dos animais de companhia ficam claramente numa posição marginal.

Os agentes que colocam em prática as competências da DGAV são os médicos veterinários municipais. À semelhança do já descrito quanto às responsabilidades do DGAV, a figura do médico veterinário municipal é apenas a materialização do anteriormente mencionado. O decreto-lei 116/98 de 5 de Maio de 1998 é disso espelho:

\section{Artigo $2^{\circ}$}

[...]

3 - Os poderes de autoridade sanitária veterinária são conferidos aos médicos veterinários municipais, por inerência de cargo, pela Direcção-Geral de Veterinária (DGV), enquanto autoridade sanitária veterinária nacional, e pela Direcção-Geral de Fiscalização e Controlo da Qualidade Alimentar (DGFCQA), a título pessoal, não delegável e abrangendo a actividade por eles exercida na respectiva área concelhia, quando esteja em causa a sanidade animal ou a saúde pública.

4 - O exercício do poder de autoridade sanitária veterinária concelhia traduz-se na competência de, sem dependência hierárquica, tomar qualquer decisão, pornecessidade técnica ou científica, que entenda indispensável ou relevante para a prevenção e correç̧ão de factores ou situações susceptíveis de causarem prejuízos graves à saúde pública, bem como nas competências relativas à garantia de salubridade dos produtos de origem animal.

$[\ldots]$

Artigo 4.

1 - Os médicos veterinários municipais dependem, hierárquica e disciplinarmente, do presidente da câmara da respectiva área da sua intervenção. (DIÁRIO DA REPÚBLICA, 1998).

Assim, a par de todas as actividades que envolvam animais e/ou produtos de origem animal (e que podem incluir a produção e/ou a comercialização dos mesmos), 
cabe ao médico veterinário também olhar pelo bem-estar dos animais de companhia que habitam o território abrangido pelo município para o qual trabalha. É possível que um médico veterinário que se ocupe de funções desta natureza comece o seu dia num aviário e o termine em iniciativas de esterilização de animais errantes.

Para se entender por completo o contexto em que o acontecimento em causa ocorreu, é necessário analisar por partes as instituições, os humanos envolvidos e o modo como estes percepcionam os não-humanos cativos nos locais em causa.

\section{Os animais de companhia na qualidade de "cidadãos decentes"}

Não obstante a posição da administração central em relação ao significado actual dos animais de companhia na sociedade portuguesa, a verdade é que de um ponto de vista sociozoológico (ARLUKE; SANDERS, 1996) esta é uma matéria em que as entidades competentes se deveriam debruçar substancialmente mais. Hoje sabe-se que os animais de companhia são promotores da saúde mental, da saúde física, de hábitos mais sustentáveis e a sua existência nos lares nacionais contribui para a economia do país.

Nas denominadas sociedades ocidentais, os animais de companhia gozam de um estatuto muito semelhante ao dos seres humanos (LEACH, 1964), ocupando um lugar singular na sua escala sociozoológica (ARLUKE; SANDERS, 1996). Com efeito, os animais de companhia enquadram-se no patamar hierárquico dos "bons animais" que são assim considerados por "aceitarem" a sua posição de subordinados às vontades dos seus companheiros humanos (ARLUKE; SANDERS, 1996). Os cães, por exemplo, têm um leque de bens e serviços ao seu dispôr que é muito esclarecedor sobre o seu papel e importância: cabeleireiros, vestuário, agências matrimoniais, escolas de educação canina, etc. Tudo parece ser válido para os tornar progressivamente mais antropomórficos, no sentido de camuflar o mais possível as suas características “animais" (FRANKLIN, 1999).

Os animais de companhia são uma espécie de extensão da identidade do humano com quem o não-humano estabelece uma relação interespecífica (SANDERS, 1999). O primeiro passo para que tal aconteça é o momento do baptismo do não-humano (BECK; KATCHER, 1996). É a partir do momento da atribuição de um nome próprio que nos vemos obrigados a tratá-lo de forma diferente dos restantes animais não-humanos confirmando a sua singularidade (BECK; KATCHER, 1996).

Para que mantenham o seu estatuto de "bons animais", têm que ser capazes de estar à altura do desafio. Isto é, deverão comportar-se como "seres moralmente 
elevados", "cidadãos decentes" e "vassalos" da sociedade em que estão inseridos (ARLUKE; SANDERS, 1996). Passar para o lado dos "maus animais" é fácil: basta um pequeno deslise que indique que o não-humano poderá estar a tentar subverter a hierarquia imposta pela espécie dominante, a humana (ex: morder um dos seres humanos da família, vocalizar durante a noite, arranhar o mobiliário ou um descuido no chão de casa). Quando tal acontece, a probabilidade de um abandono ou de uma eutanásia aumenta substancialmente.

Por se tratarem de não-humanos que gozam de elevado estatuto nas nossas sociedades, não sendo a portuguesa uma excepção, não é de surpreender a onda de choque que atingiu a opinião pública na sequência dos factos aqui já relatados.

\section{Os animais de companhia na qualidade de "cidadãos decentes"}

Os contornos da existência destes dois abrigos não são suficientemente claros. Sendo ilegais, os abrigos eram do conhecimento do médico veterinário municipal, do Presidente da Câmara Municipal de Santo Tirso, da DGAV e, pelo menos, também do Ministério Público. As condições precárias em que estes animais de companhia eram albergados eram também do conhecimento geral. No entanto, pelo menos, cerca de centena e meia de animais eram mantidos cativos nestes locais.

O cenário encontrado por quem se voluntariou para resgatar os "habitantes" dos abrigos incluía fezes, mau-cheiro, comedouros vazios de comida e água, cães e gatos mortos, animais feridos, doentes, e não raramente presos por correntes. Existe ainda o testemunho de um voluntário que reencontrou um cão que teria "perdido" dois anos antes e que era detentor de "microchip" de identificação devidamente registado na base de dados do Sistema de Informação de Animais de Companhia (SIAC) (NOTÍCIA AO MINUTO, 2020). Não sendo nosso propósito fazer um diagnóstico, defendemos que podemos estar na presença de dois casos (mãe e filha, proprietárias de ambos os abrigos) de uma perturbação de ansiedade denominada Desordem de Acumulação de Animais (Animal Hoarding Disorder) ou DAA.

Patronek (1999) caracteriza esta perturbação da seguinte forma: detenção de um número excessivo de animais, sem que lhes sejam prestados cuidados adequados, sem que haja consciência disso e sendo frequente que - quem desta desordem mental padece - negue a sua incapacidade para cuidar dos mesmos. Nos últimos anos, a literatura sobre este assunto tem sido crescente (DOZIER et al., 2019, ARLUKE et al., 2017, FERREIRA et al., 2017, UNG et al., 2017, OCKENDEN; DE GROEF; MARSTON, 2014, BERRY; PATRONECK; LOCKWOOD, 2005), mas as autoridades continuam a 
mostrar dificuldade em detectar estes casos e prevenir recidivas.

Para o conhecimento desta perturbação de ansiedade também tem contribuído a divulgação de mais casos: por exemplo, as investigações das instituições de controlo animal referem aproximadamente 3000 novos casos de acumuladores de animais detetados anualmente só nos EUA (PATRONECK, 2006). Entretanto o estudo publicado por Ferreira et al. (2017) sobre 33 residências de indivíduos que sofrem desta perturbação no Sul do Brasil também nos mostra o que se pode supor para o resto deste país.

Numa percentagem considerável de situações, os acumuladores de animais também já exibiram sinais evidentes de perturbação por serem igualmente acumuladores de objectos (DOZIER et al., 2019).

Existem ainda outros factores que parecem contribuir para que determinados indivíduos apresentem uma maior probabilidade de se tornarem acumuladores de animais. Patroneck (2015) chega a identificar um conjunto de traços presentes nos indivíduos que exibem esta perturbação. Um padrão comum a muitos deles é a existência de histórias de vida marcadas por instabilidade e incerteza do ponto de vista parental. Muitos foram vítimas de negligência e abuso. Quando adultos, estes indivíduos mostram dificuldades em estabelecer e manter uma relação interpessoal saudável com os seus pares. Muitos deles foram ainda vítimas de traumas múltiplos durante a infância ou até durante vida adulta (abuso sexual, abandono parental, morte ou perda inesperada de indivíduos importantes nas suas vidas como filhos ou cônjuges, por exemplo). Estatisticamente os acumuladores de animais tendem a ser mulheres solteiras, divorciadas ou viúvas, que poderão também viver em isolamento social e/ou com outras pessoas que de si dependem [i.e. crianças, idosos ou pessoas portadoras de deficiência (ARLUKE et al., 2017)]. Esta desordem implica uma compulsão profunda para manter ou aumentar o número de animais apesar da evidência de que não se possue condições para tal. Não obstante, quando contrariados nesse propósito ou quando lhes são retirados os animais, estes indivíduos apresentam elevados graus de ansiedade e de profundo sofrimento (PATRONECK, 2015).

Quando é dado o alerta, geralmente parte de vizinhos, os animais são sempre encontrados em situação de grande precariedade. Os relatos são praticamente sempre os mesmos: fezes acumuladas, forte odor a urina, cadáveres de outros animais, lixo, subnutrição e doenças infecto-contagiosas que colocam em risco os animais, as pessoas que com eles convivem e a comunidade em geral. Na verdade estes locais constituemse como verdadeiros perigos não apenas para os animais que albergam mas também para a própria saúde pública uma vez que daí podem surgir o mais variado tipo de zoonoses.

A maioria dos não humanos sobreviventes acaba por necessitar de cuidados 
médicos e só muito dificilmente apresenta estabilidade comportamental suficiente para ser adoptado posteriormente (DOZIER et al., 2019).

Não havendo um procedimento ou protocolo estabelecidos para lidar com este tipo de perturbação de ansiedade, o indivíduo que acumula compulsivamente animais nunca chega a ser ajudado com assistência adequada, o que contribui para que praticamente $100 \%$ dos casos reincidam (BERRY; PATRONECK; LOCKWOOD, 2005, DOZIER et al., 2017, PATRONECK, 1999).

Arluke et al. (2017), defendem que a acumulação de animais é mais complexa do que a acumulação de objectos, uma vez que o leque de motivações é mais complexo e pode diferir de acumulador de animais para acumulador de animais. É nesta esteira que dividem estes indivíduos em três grupos distintos:

a) O cuidador assoberbado (overwhelmed caregiver) que é o que vai diminuindo, ao invés de negar na totalidade, os cuidados prestados aos animais que se encontram sob a sua tutela. Geralmente, tal é o resultado de uma perda repentina de rendimentos ou o surgimento de problemas de saúde. Apesar da sua forte ligação aos animais, a situação do cuidador assoberbado leva a uma gradual deteriorização das condições sanitárias em que se encontram os não humanos que tem ao seu cuidado.

b) O cuidador salvador (rescuer hoarder) é o que se constitui como o maior problema porque, na generalidade, é o que tem maior número de animais (podendo exceder 500 cães ou gatos). Estes indivíduos assumem para si a responsabilidade de salvar todos os animais, sobretudo se a hipótese de eutanásia se colocar. Olham para as instituições de controlo e cuidado de animais como um inimigo e, não raras vezes, não concordam com as abordagens clínicas da medicina veterinária convencional. O que distingue estes indivíduos dos que se envolvem na causa animal de forma legítima é a sua total incapacidade para manter registos actualizados dos animais que estão à sua guarda, para ter uma equipa de colaboradores estável, providenciar cuidados médicos e a incapacidade para recusar albergar mais animais em caso de sobrelotação.

c) O tipo de acumulador que mais desafia as autoridades é o "acumulador explorador" (exploiter hoarder). Tratam-se de indivíduos sociopatas que exibem uma total ausência de empatia por seres humanos e por animais. São geralmente motivados pelos ganhos económicos que os animais podem proporcionar. Empenham-se em promover peditórios constantes que nunca são verdadeiramente canalizados para a causa que dizem defender. São carismáticos, socialmente hábeis, muito competentes e são especialmente 
talentosos a ludibriar os media e os agentes da autoridade.

Mas existem diferenças adicionais entre a desordem de acumulação de objectos e a DAA: a acumulação de animais, ao contrário da acumulação de objectos, não obstrui os lugares domiciliários (FERREIRA et al, 2017). Adicionalmente, ao contrário da relação das pessoas com os objectos, no caso da DAA existe um laço entre pessoas e animais (FERREIRA et al, 2017). Estas diferenças apontadas por Ferreira et al. (2017) caracterizam a DAA como uma nova desordem mental que pode gerar um interesse considerável para ambos profissionais e investigadores.

Independentemente das motivações que estarão na origem da acumulação de animais, a verdade é que a mesma deverá ser sempre tratada sob dois pontos de vista: a) a necessidade de quem a pratica ser encaminhado para um plano de tratamento, após responder perante as autoridades, para se tratar e para também prevenir a grande probabilidade de recidiva; $b$ ) a necessidade de encaminhar as vítimas/sobreviventes para locais seguros onde lhes possa ser prestada ajuda adequada e assegurar, sempre que possível, a sua adopção.

Apesar dos efeitos nefastos da acumulação de animais para todas as partes envolvidas, esta desordem de ansiedade não consta no manual de perturbações da Associação Americana de Psiquiatria como um distúrbio totalmente independente. A DAA é classificada como uma variante dos distúrbios obsessivo-compulsivos, o que poderá também estar na origem da sub-valorização dos seus efeitos (DOZIER et al., 2019, ARLUKE et al., 2017, FERREIRA et al., 2017, BERRY; PATRONECK; LOCKWOOD, 2005).

\section{Objectivo do estudo}

A ignorância relativa à acumulação de animais enquanto perturbação de ansiedade tem eco nas mais variadas esferas da vida social, trespassando vários atores sociais que vão desde o cidadão comum até às autoridades ou às organizações de proteção dos animais. Por exemplo, os retratos divulgados pelos media falham em trazer luz à realidade do problema bem como às suas próprias consequências (BERRY; PATRONECK; LOCKWOOD, 2005, ARLUKE et al., 2002).

O presente artigo tem por base publicações de Facebook ${ }^{2}$ de duas organizações defensoras da causa animal, a ANIMAL e Intervenção e Resgate Animal (IRA) que,

\footnotetext{
${ }^{2} \mathrm{~A}$ rede social Facebook foi a escolhida por ser a que conta com um maior e mais heterogénio número de utilizadores.
} 
durante o evento e nos dias subsequentes, foram responsáveis por publicações relacionadas com os incêndios florestais que estiveram alegadamente na origem da morte dos animais de companhia mantidos no interior dos dois abrigos ilegais.

Recorrendo exclusivamente à etnografia digital (KOZINETS, 2015; VARIS, 2016), o objectivo foi captar a interpretação que estas duas organizações e os seus seguidores fizeram do acontecimento e onde estas mesmas se situam no eixo crime/acumulação de animais.

\section{Material e Métodos}

Tal como mencionado no ponto anterior, foram escolhidas duas organizações ligadas à causa animal. Os critérios que estiveram na base da nossa escolha prenderamse com: a) o caractér interventivo de ambas as organizações; b) o facto de publicarem no Facebook com regularidade; c) o número elevado de seguidores activos (o que, à partida, garantiria uma variedade considerável de dados).

A organização ANIMAL foi fundada em 1994. Tem por objectivo desenvolver campanhas de educação e de informação para o público em geral acerca dos nãohumanos (características, necessidades, interesses e direitos fundamentais). Desenvolve também campanhas de alerta e protesto, investigações especiais e denúncias públicas, trabalho de relações públicas e acções judiciais sempre que detecta situações em que possam existir não-humanos em risco. Desenvolve também acções de lobbying político, com vista à promoção dos direitos dos animais e à sua proteç̧ão legislativa. Não sendo o seu objectivo principal, presta também apoio a não-humanos individuais dependendo da sua situação clínica e familiar. Tem aproximadamente 127.000 seguidores no Facebook e está presente na rede desde $2009^{3}$.

A organização IRA, foi fundada em 2016 e desenvolve acções mais focadas no resgate de animais vítimas de negligência e/ou maus-tratos. Funciona com base em denúncias e, de acordo com a sua página de Facebook, colabora com as autoridades oficiais sempre que solicitado. Quanto ao seu estatuto jurídico, não é disponibilizada informação, pelo que não se sabe se se trata oficialmente de uma ONG. Os seus membros não são publicamente conhecidos uma vez que quando aparecem em público, procuram esconder a sua identidade usando óculos escuros ou tapando parte da face. A IRA tem atualmente cerca de 350.000 seguidores e existe no Facebook desde $2016^{4}$.

\footnotetext{
3 https://www.facebook.com/ONGANIMAL/

${ }^{4}$ https://www.facebook.com/intervencaoeresgateanimal/
} 
Ambas as organizações dependem de donativos de privados e, pelo menos a ANIMAL, de outras organizações ligadas à causa.

\section{Recolha de dados}

Foram analisadas todas as publicações no Facebook que revelaram narrativas e discursos com uma relação directa com os factos relatados na introdução, bem como os comentários que se lhes seguiram. As mesmas compreenderam o período entre 19 e 28 de Julho de 2020, não porque não tenham surgido publicações relacionadas com o acontecimento em causa posteriormente, mas porque foi nessa altura que demos por terminada a recolha dos dados e era necessário encontrar uma linha de corte na cronologia de cada um dos murais. Adicionalmente e como se poderá verificar posteriormente neste trabalho, o número de publicações relacionadas com o sucedido foi decrescendo de forma muito significativa ao longo do período em análise (nove dias).

No que aos comentários de seguidores diz respeito, e dado o elevado volume de reacções a algumas das publicações, os mesmos foram seleccionados respeitando um intervalo de 10 , sendo seleccionados no máximo 30 por cada uma das publicações. A cada dezena de comentários, seleccionou-se para análise o $11^{\circ}$ comentário (desde que o mesmo surgisse em forma de texto). Sempre que o $11^{\circ}$ comentário era constituído apenas por uma imagem (emoji, gif, etc.) - para não introduzir uma carga excessiva de subjectividade - seleccionou-se o comentário em texto que surgisse imediatamente a seguir.

Para efeitos desta investigação, considerou-se "comentário" apenas os comentários principais, não entrando em linha de conta com comentários a comentários. A selecção foi feita com base na totalidade de comentários às publicações e não apenas com base nos comentários mais recentes, mais antigos ou mais relevantes cuja classificação depende totalmente do algoritmo do Facebook.

\section{Análise dos dados}

A análise foi feita com base nos pressupostos da análise de conteúdo (BARDIN, 2009), usando a frase como unidade de significação, cuja categorização seguiu o trabalho realizado por Arluke et al. (2002) que teve por base artigos de imprensa norte- 
americanos sobre indivíduos que sofrem de DAA. Tratando-se de uma análise que recai sobre um objecto de estudo diferente, procedemos a algumas adaptações no sentido de conseguir encaixar nas categorias pré-estabelecidas o maior número de unidades de significação possível.

O estudo em causa (ARLUKE et al., 2002) aponta cinco abordagens jornalísticas ligadas a cinco eixos emocionais (emotional themes) distintos:

a) Drama: a abordagem mais frequente é a que reporta histórias de acumuladores de animais de um ponto de vista do crime e focando-se esmagadoramente em fontes ligadas à criminalização do comportamento. As autoridades são chamadas ao local onde encontram um número supreendente de animais mortos ou em sofrimento e que, por acção das mesmas, são retirados ao tutores que enfrentarão acusações de maustratos que poderão culminar em prisão (ARLUKE et al., 2002).

Para a análise que levámos a cabo, acrescentámos nesta categoria frases que nos remetessem para, não só a existência da prática de um crime por parte das proprietárias, mas também para potenciais condutas negligentes por parte das autoridades competentes (Guarda Nacional Republicana, DGAV, Câmara Municipal de Santo Tirso, Veterinário Municipal, etc.), considerando que para a ANIMAL e para a IRA e os seus seguidores poderiam igualmente configurar a prática de um comportamento criminoso.

b) Repulsa: algumas matérias jornalísticas concentram-se no modo de vida do indivíduo que sofre de DAA (e estende-se aos não humanos que com ele vivem). Geralmente, versam sobre a falta de condições de higiene do seu domicílio e a forma como isso desafia as regras ligadas à ordem, limpeza e segurança da comunidade. Geralmente, ofuscam o sofrimento dos não-humanos em benefício do estado de horror sanitário em que vive o acumulador (ARLUKE et al., 2002).

Ao descrito, acrescentámos descrições da falta de salubridade dos abrigos em questão e o sofrimento daí decorrente para os animais que neles viviam.

c) Pena: os acumuladores são retratados como pessoas tristes. Procura-se apresentar uma explicação científica para o comportamento em questão. Os comentários dos pretensos especialistas na matéria carecem de vocabulário e terminologia correcta ou de explicações consistentes. Estas pessoas são muitas vezes comparadas a outras que sofrem de adição ou de compulsões de vária ordem. Os indivíduos que sofrem de DAA nunca são descritos como criminosos ou mentalmente doentes, mas como indivíduos caridosos que não conseguem ver os efeitos nocivos das suas boas intenções. Não são casos de abuso, são casos de amor pelos animais que foram longe de mais (ARLUKE et al., 2002).

d) Indignação: o acumulador é descrito pela comunidade como uma pessoa exemplar e a quem qualquer um confiaria os seus animais de companhia, mas acaba por 
se revelar uma pessoa mentalmente doente capaz de abusar e de negligenciar os mesmos (ARLUKE et al., 2002).

Para o caso, decidimos que também poderiam fazer parte desta categoria unidades de significação relacionadas com o facto das instituições envolvidas terem comprometido a confiança nelas depositada pelos cidadãos.

e) Humor: tratam-se de artigos jornalísticos que se dedicam mais a descrever curiosidades sobre os acumuladores, do que a descrever a sua conduta patológica ou as consequências da mesma do ponto de vista do sofrimento dos sobreviventes (ARLUKE et al., 2002).

Foram aqui inseridas também frases em que a ironia e o sarcasmo se encontram presentes.

Os cinco eixos emocionais descritos apresentam uma imagem inconsistente da acumulação de animais que confunde o público em relação à natureza e significado deste comportamento. Não raramente, o público oscila entre considerar o acumulador um criminoso que deve ser exemplarmente punido e/ou um doente mental que necessita de ajuda profissional especializada (ARLUKE et al., 2002).

Com base nas publicações das duas organizações e nos comentários que se lhes seguiram, é nossa intenção encaixá-los numa das cinco categorias encontradas por Arluke et al. (2002) e perceber quais as mais prevalentes.

\section{Resultados}

Ao todo foram analisadas 23 publicações a que corresponderam 31.357 comentários.

\section{IRA - Intervenção e Resgate Animal}

Durante o período em análise foram feitas 21 publicações, sendo que duas eram vídeos que não entraram nesta análise, pelo que contabilizámos apenas 19. A esmagadora maioria das publicações limitou-se a prestar esclarecimentos sobre o modo como a organização IRA estava a actuar no local. Geralmente, estas publicações tiveram início com palavras como "actualização", "informação importante" ou "comunicado". Trataram-se de mensagens de cariz informativo e com pouca carga emotiva.

No entanto, à medida que os acontecimentos foram progredindo no terreno, $\mathrm{o}$ nível de emotividade dos textos foi-se tornando mais intenso o que também se traduziu 
num muito maior número de interacções dos seguidores do mural visível logo nos primeiros dois dias do período em causa (gráfico 1). No primeiro dia - 19 de Julho foram feitas cinco publicações, no segundo publicaram-se quatro textos a propósito do resgate dos animais, no terceiro houve três publicações, no quarto apenas uma, três no quinto dia, dois no sexto e, após uma interrupção de quatro dias, surge uma última publicação no dia 28 de Julho.

Dado o volume mais elevado de publicações no início dos acontecimentos, não é surpreendente que seja precisamente nessa altura que se registou um volume mais elevado de interacções por parte dos seguidores do mural. Todavia, também é de sublinhar que a natureza do evento e a possibilidade de já existirem vítimas mortais naquele momento poderá ter contribuido igualmente para a exaltação das pessoas que seguem esta organização.

Gráfico 1 - Interacções dos seguidores do mural entre 19/07/2020 e 28/07/2020

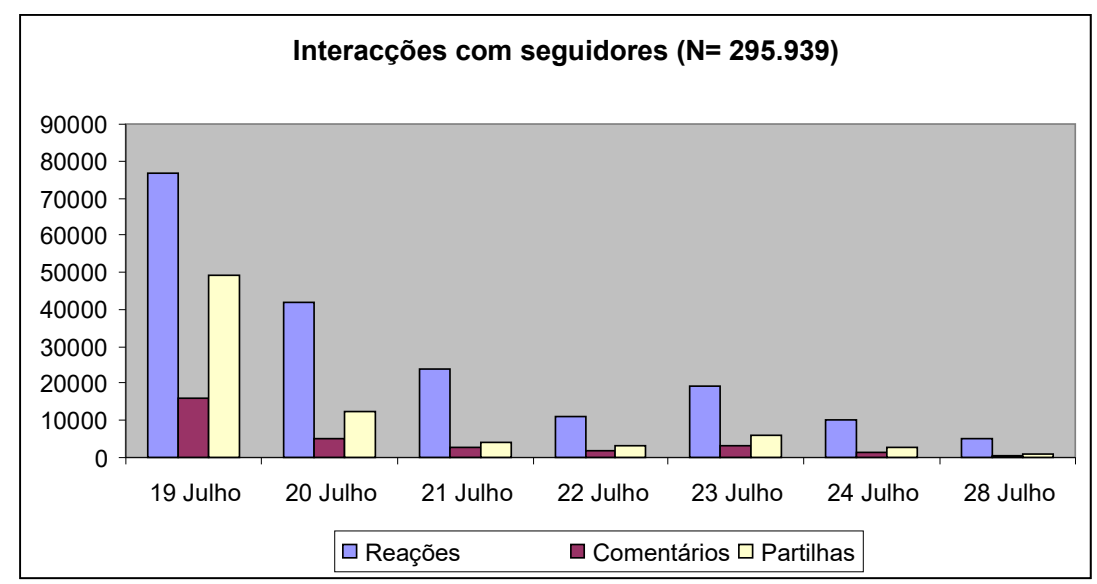

Fonte: Elaborado pelas autoras.

Quanto à categorização das publicações (gráfico 2), existiu uma clara tendência para a utilização da categoria "Drama" e essa tendência aparentou ser bastante constante ao longo do período analisado. Esteve presente em todos os dias em que foram feitas publicações associadas ao acontecimento em causa. Frases como: "Meios judiciais estão já a ser igualmente accionados para a aquisição de mandatos para entrar em propriedades privadas com a Guarda Nacional Republicana." ou "Esta tragédia não pode, nem irá morrer sozinha." ou ainda "Existe uma investigação a decorrer e esta instituição (IRA) está articulada com o Núcleo de Investigação de Crimes e Contra-Ordenações Ambientais da GNR." São reflexo do modo como a organização agora em análise viu o 
acontecimento, bem como as suas consequências, como um crime que requer punição.

Gráfico 2 - categorização das publicações

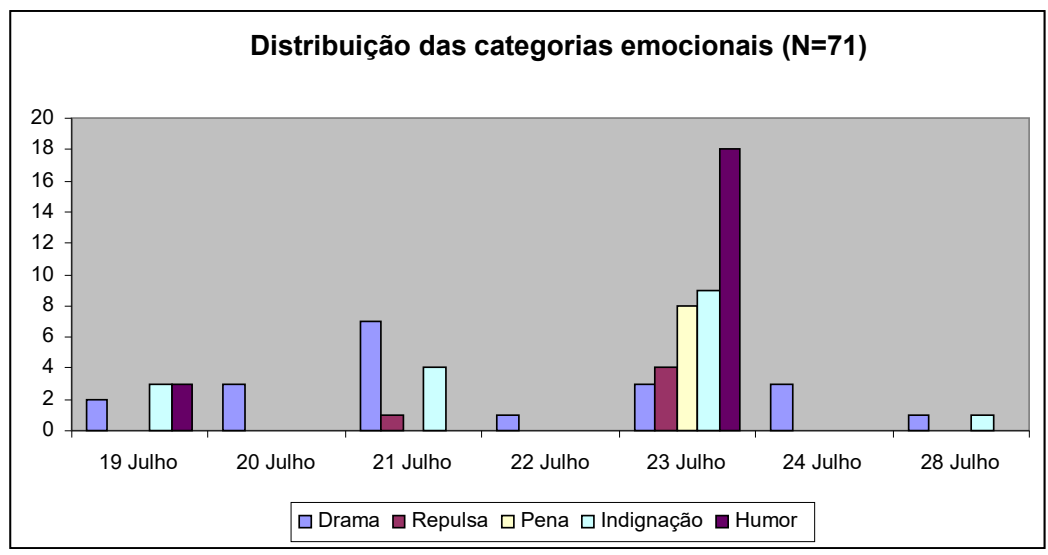

Fonte: Elaborado pelas autoras.

A categoria "Indignação" também esteve presente em praticamente todo este período de nove dias e prendeu-se sobretudo com a alegada incompetência/inércia na resolução do problema atempadamente. Esteve muito patente a ideia de que houve uma falha grave e transversal na actuação de todas as autoridades envolvidas (desde o poder local ao poder central). Ex: "Tenta-se agora apurar os responsáveis pela inércia prétragédia, enquanto se choram as vidas pós-desastre."

As restantes categorias foram surgindo aqui e ali, uns dias mais outros menos, no entanto gostaríamos de sublinhar duas categorias que, embora muito resíduais, farão alguma diferença no modo como os seguidores poderão passar a ver a questão. No dia 23 de Julho, no rescaldo do resgate dos animais sobreviventes, a organização publicou um longo texto onde as categorias "Pena" e "Humor" surgiram muito marcadas. Ambas procuraram complementar e até reforçar a ideia de as instituições oficiais envolvidas em todo o processo tiveram uma conduta reprovável.

Por um lado, o conteúdo da publicação indica-nos que houve uma quase desculpabilização do comportamento de uma das proprietárias de um dos abrigos atingidos pelo incêndio (ex: "Mas apercebi-me de uma coisa quando falei com a proprietária deste abrigo. Só precisava de ajuda!") que não pode ser exemplar porque as autoridades competentes não executaram bem o seu trabalho (ex: "Contam-se pelos dedos de 2 mãos os abrigos LEGALIZADOS pela DGAV, de Norte a Sul do país ou arquipélagos. Como tal, chamar de "abrigo ilegal" não significa que se trate de um matadouro, depósito de animais ou ponto de tráfico".). 
Por outro lado, a mensagem foi igualmente rica em trechos de humor sarcástico e de ironia que visaram as instituições que alegadamente falharam à sociedade civil e aos animais de companhia que se viram envolvidos no incidente. Com efeito, das 42 frases categorizadas e que correspondem às publicações do dia 23 de Julho, 18 pertencem à categoria "Humor": "Eu não estou a dizer que estas acumuladoras dão cá um jeitaço aos GMVM e protectores de animais para escoar os animais dos canis e fazerem brilharetes nas redes sociais."

Curiosamente, esta foi também a única vez em que as publicações da organização IRA, durante este período de tempo, mencionaram a expressão "acumulação de animais". Contudo, não é de todo claro se neste comentário houve efectivamente um entendimento da condição mental das proprietárias ou se se tratou apenas de um efeito do tom irónico adoptado nesta publicação em concreto.

Dos comentários seleccionados (gráfico 3), a totalidade foi de apoio às publicações e, não raras vezes, chegaram até a ser mais contundentes do que as próprias publicações sobretudo no que à necessidade de se fazer justiça diz respeito. A esmagadora maioria dos comentários foram feitos por mulheres $(90,5 \%)$. No entanto, os seguidores homens que teceram comentários às publicações fizeram-no quase sempre com recurso a um discurso mais agressivo e que, não raramente, incluiu vocabulário "menos próprio" e até insultuoso.

Gráfico 3 - Comentários seleccionados/género

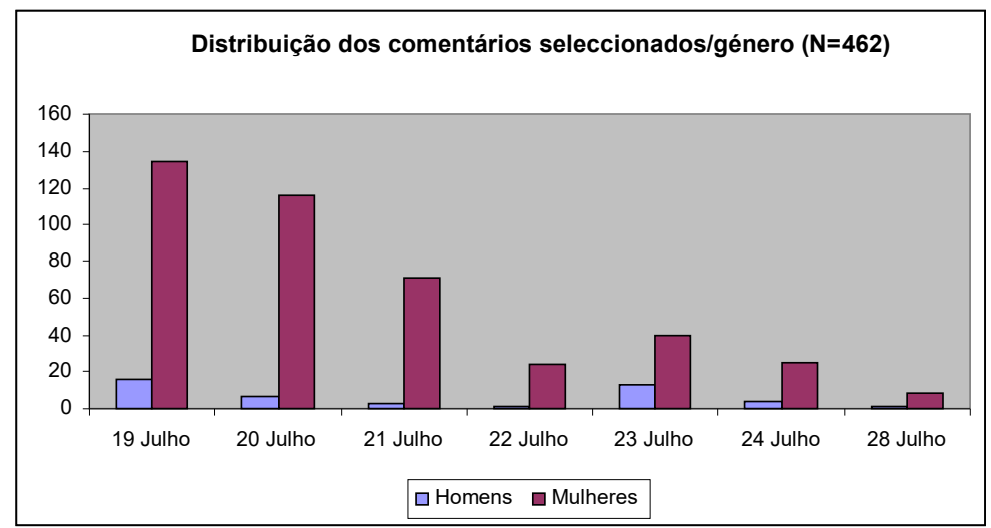

Fonte: Elaborado pelas autoras.

\section{ANIMAL}

Durante o período em análise, a organização ANIMAL fez cinco publicações 
relacionadas com o incêndio que atingiu os dois abrigos. Todas eram constituídas por texto, mas uma delas incluiu um vídeo e, por esse motivo, essa publicação não foi considerada no presente trabalho. O número de interacções com o mural, a propósito do incidente, foi substancialmente mais elevado no início do período em análise (sobretudo a 19 de Julho) e decresce abruptamente logo após o acidente (gráfico 4). Na prática, a actividade do mural em relação ao acontecimento em análise, resumiu-se a dois dias.

Gráfico 4 - Número de interacções com o mural - 19/07/2020 e 28/07/2020

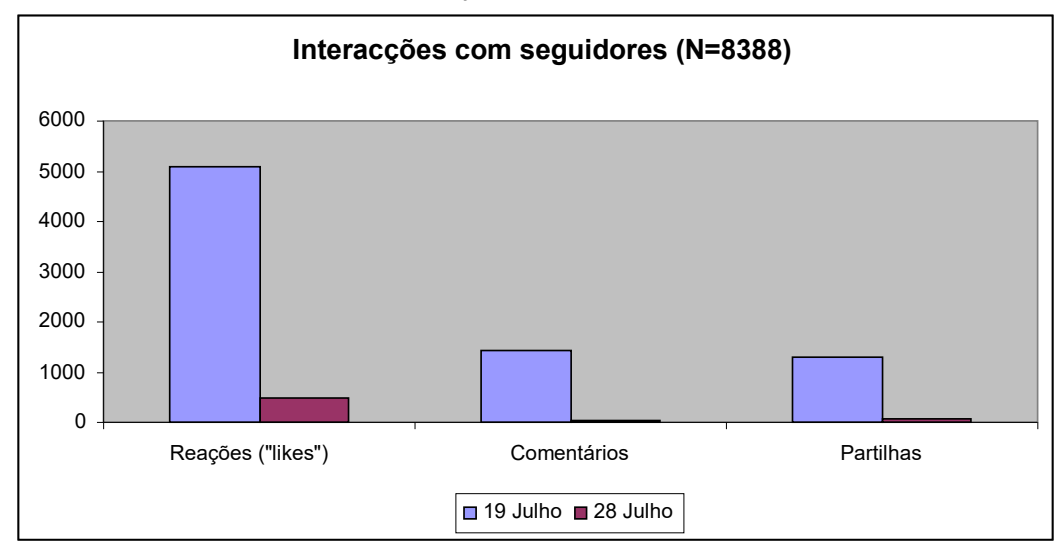

Fonte: Elaborado pelas autoras.

Todas as publicações tiveram por objectivo prestar informações claras sobre o acontecimento em análise e sobre o facto de a ANIMAL pretender encetar diligências para o apuramento dos factos. Na generalidade, não foram dados detalhes sobre o que se encontrava a ser feito. Em apenas três das publicações existiu efectivamente matéria para análise, embora muito parcamente, e a mesma concentrou-se no início do período analisado (gráfico 5). A categoria "Indignação" foi a que mais marcou lugar, correspondendo a $60 \%$ do total das frases classificadas. Esmagadoramente, as mesmas dirigiram-se à actuação das autoridades, muito particularmente à GNR: "Segundo pudemos apurar, as autoridades policiais locais não estão a permitir o apoio aos animais, estando até presente no local uma Deputada à AR, a deputada Bebiana Cunha, deputada pelo PAN, e nem essa presença parecem respeitar." Aliás, das três publicações de dia 19 de Julho - momento especialmente activo no mural da ANIMAL - duas visaram directamente a actuação da GNR e do médico veterinário municipal. Isso poderá explicar o número maior de frases classificadas como "Indignação". No final do período analisado, existiu um único registo de "Humor" a propósito da demissão do DirectorGeral da DGAV. Assinalamos, no entanto, a total ausência da categoria "Pena". Não 
existiu, ao longo das publicações qualquer menção à condição das proprietárias dos abrigos, quer como potencialmente autoras de um crime, quer como potenciais acumuladoras de animais.

Gráfico 5 - Categorias Emocionais - 19/07/2020 e 28/07/2020

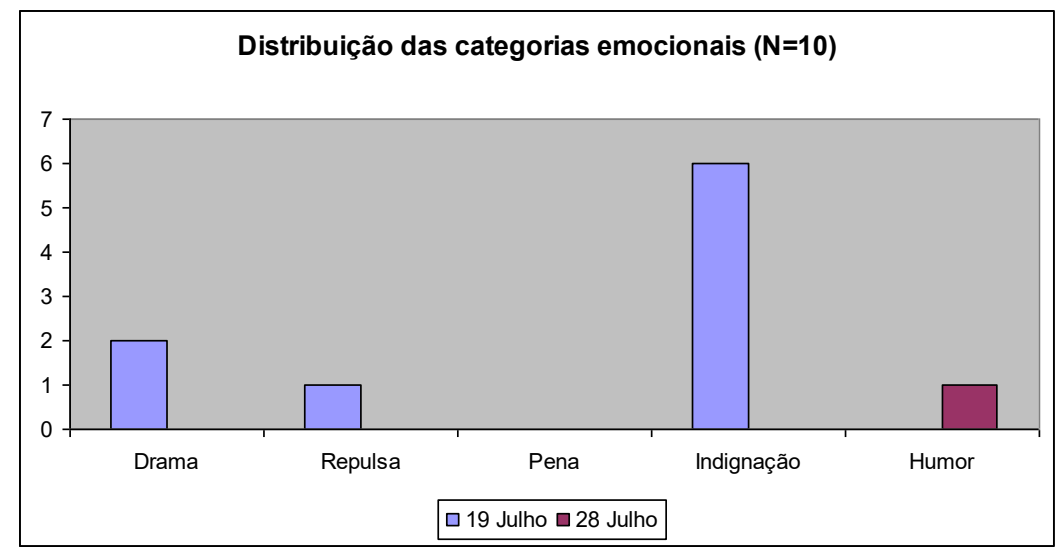

Fonte: Elaborado pelas autoras.

Quanto aos comentários publicados por seguidores da organização ANIMAL, $87,6 \%$ foram mulheres (gráfico 6). Todos eles foram manifestações de apoio à actuação da organização ANIMAL, com excepção de dois comentários. O primeiro surgiu após a divulgação de uma vígilia de protesto contra a actuação das autoridades no local dos incêndios e que nada teve a ver com o propósito desta, mas sim com o facto de estarmos a viver uma pandemia ("Fiquem mas é em casa, e a pandemia? As pessoas não se lembram que estamos a lutar contra uma coisa que não sabemos a força dela daqui por diante, nada de ajuntamentos, nada de manifestações, FIQUEM EM CASA!!!”). A segunda surgiu na sequência do comunicado emitido pela GNR com vista a esclarecer o público quanto à actuação desta força de segurança no local do incidente e procurou chamar à atenção para o facto de estarmos perante a morte de não humanos e provavelmente como forma de desculpar as forças de segurança do sucedido: "Em 15 dias morreram 2 Bombeiros e outros estão em estado bastante grave, têm menos valor que cães." O primeiro comentário partiu de uma seguidora, o segundo de um seguidor. 
Gráfico 6 - Comentários Publicados por Seguidores da Organização ANIMAL

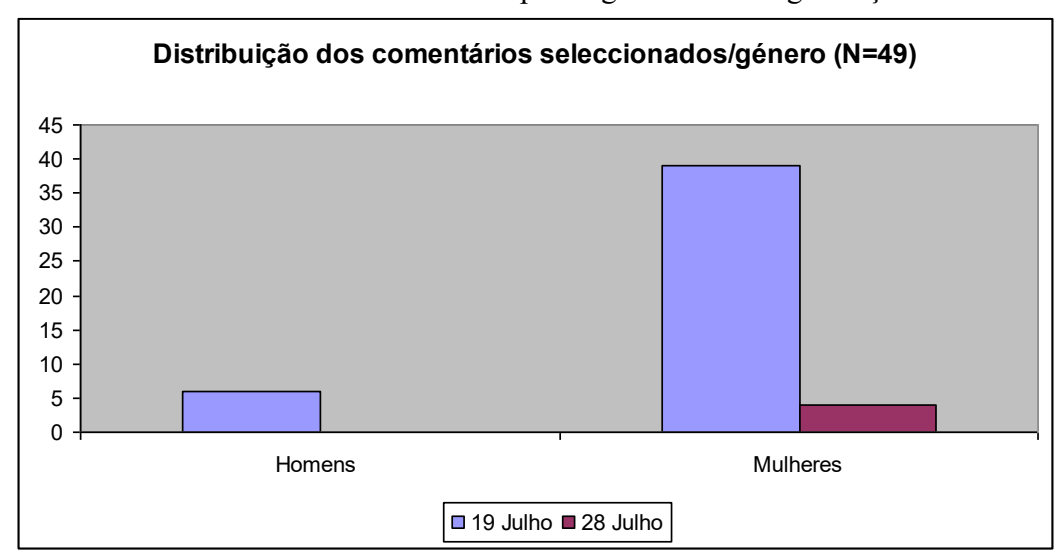

Fonte: Elaborado pelas autoras.

De sublinhar que, numa dessas publicações, a associação ANIMAL pediu aos seguidores que se privassem de fazer comentários que contivessem insultos ou ameaças, pedido que é muito comum no discurso publicado por esta organização que acredita poder demover alguns seguidores de discursos insultuosos e ameaçadores. Importa referir que apesar de estar totalmente fora do nosso alcance poder confirmá-lo, existe a possibilidade do administrador do mural apagar comentários que possam ferir susceptibilidades se assim o desejar.

\section{Discussão}

Enquanto que a organização IRA se envolveu activamente no resgate dos animais cativos nos abrigos, a organização ANIMAL acompanhou o desenrolar dos factos fora do contexto em que os mesmos efectivamente ocorreram. Ambas as organizações afirmam terem encetado diligências no sentido de garantir o apuramento de responsabilidades.

Ambas as organizações (IRA e ANIMAL) publicaram e apresentaram actividade relacionada com os acontecimentos de Santo Tirso nas suas páginas (e respectivos murais) de Facebook. Ambas exibiram - no período de 19 a 28 de Julho um nível elevado de interacções com os seus seguidores, sendo que o dia em que o incidente foi tornado público (dia 19) foi um momento de actividade especialmente intensa. Existem, no entanto, diferenças muito substanciais entre as publicações de ambas as organizações. 
A associação IRA apostou em publicações de texto com vocabulário menos diversificado, todavia capaz de causar mais impacto nos seguidores e, consequentemente, originando um número substancialmente maior de interacções com as publicações presentes no mural. Em nenhuma destas publicações foram impostos limites quanto a potenciais insultos ou ameaças. O mural foi, durante todo este período, bastante activo e nele as publicações foram aproximadamente cinco vezes mais do que as visíveis no mural da organização ANIMAL.

Por sua vez, a ANIMAL, fez publicações mais objectivas. Limitou-se muitas vezes a difundir vídeos de excertos de noticiários de televisão em que membros da organização participaram e matérias jornalísticas sem tecer considerações adicionais. $\mathrm{O}$ comportamento desta organização obedeceu mais a um simples relato dos factos. A excepção aconteceu apenas no dia do incêndio, altura em que as publicações originaram um maior número de interacções que, ainda assim, não tiveram comparação com os valores apresentados pela associação IRA. A própria natureza da actividade da organização ANIMAL - abertamente de lobby junto do poder político, nomeadamente no parlamento - poderá não ser compatível com publicações mais "emotivas" que poderiam comprometer o tipo de actividade que procuram desenvolver junto dos decisores políticos.

De uma forma geral, as categorias "Indignação", "Drama" e "Repulsa" foram as mais frequentes nas publicações analisadas. A categoria "Humor" marcou presença nas publicações de ambas as organizações, mas teve especial destaque - a determinado momento - no mural da organização IRA. Ficou de fora, quase na totalidade, a categoria "Pena" que surge de forma muito residual numa única publicação da IRA. Não é muito surpreendente, considerando que estas são páginas e murais ligados à causa animal e não aos direitos humanos.

Não será também de estranhar o número esmagador de seguidoras activas (por oposição a seguidores) destes dois murais. No Ocidente, e muito concretamente na Europa, os direitos dos animais sempre foram temas mais femininos do que masculinos (BIRKE; PARISI, 1999). Os homens, com efeito, surgem aqui de forma tímida e, uma das vezes em que tal aconteceu, foi com o objectivo de desvalorizar as vidas das vítimas não-humanas do incidente.

Finalmente, houve uma única menção à possibilidade das proprietárias dos abrigos serem acumuladoras de animais mas não ligando obrigatoriamente esta expressão à desordem mental que constitui. Apesar de as mesmas serem apontadas como autoras de um crime de maus-tratos a animais, ninguém aparentemente as percepciona como pessoas potencialmente portadoras de doença mental, neste caso a DAA. 


\section{Considerações finais}

A acumulação de animais é uma perturbação mental que, apesar de carecer de maior atenção por parte de todos, a começar pelos profissionais de saúde mental, beneficia do facto de surgir muitas vezes disfarçada de caridade e empatia para com os não humanos, especialmente os animais de companhia para não ser detectada como uma desordem psicológica. Não sendo um propósito nosso a apresentação de um diagnóstico, o facto das proprietárias recolherem animais errantes, manteve-as longe do escrutínio da comunidade e das autoridades, facto também facilitado por viverem numa área florestada consideravelmente isolada. Quando alguns cidadãos argumentaram sobre a possibilidade de se tratar de uma situação de maus-tratos, as autoridades envolvidas desvalorizaram argumentando que - não sendo uma situação ideal aquela em que os abrigos se encontravam e face ao que tinha sucedido - o que se tinha passado, não teria grande gravidade.

As sociedades contemporâneas no chamado mundo ocidental são marcadamente antropocêntricas - e essa é uma característica transversal a muitos dos actores envolvidos no caso relatado no presente artigo, incluindo decisores e agentes da autoridade. Esse antropocentrismo poderá estar na origem da forma "leve" como toda esta tragédia foi sendo tratada por quem de direito. Se ao invés de vítimas como cães e gatos, as vítimas fossem seres humanos, provavelmente as decisões tomadas, o protocolo seguido e o próprio desfecho seriam diferentes (não obstante tragédias como a de Pedrogão Grande em 2017, por exemplo, onde faleceram mais de meia centena de pessoas em condições que apresentam algumas semelhanças). Ainda assim, por se tratarem de animais de companhia que, tal como mencionado no ponto 1.1.2, beneficiam de um estatuto "confortável" na nossa escala sociozoológica, os alarmes soaram nas organizações defensoras dos direitos dos animais e na população de uma forma geral, ao ponto de, como referido anteriormente, o Primeiro Ministro se sentir na obrigação de fazer uma breve declaração ao país sobre o assunto. As ondas de choque foram sentidas do ponto de vista político, levando à demissão do Diretor-geral da DGAV e ao despedimento de veterinário municipal. A importância dos animais nas nossas sociedades é crescente (FRANKLIN, 1999, ARLUKE; SANDERS, 1996, BECK; KATCHER, 1996) e pode ser ilustrada por reacções a acidentes como este.

A DAA é provavelmente muito mais frequente na sociedade portuguesa do que desejaríamos e é difícil de detectar não apenas pelo facto de ser uma desordem pouco conhecida mas também pelo facto dos indivíduos poderem ser vistos com aparente simpatia. Isso poderá dever-se à invisibilidade dos acumuladores - que não raras vezes vivem isolados do resto da comunidade -, à inoperância das autoridades, à sobrelotação 
dos canis/gatis municipais e à forma especista como estes assuntos são tratados em sede própria (quando o são).

Para efeitos da saúde pública e do bem-estar animal, seria fundamental que este fenómeno fosse identificado e regularmente monitorizado. Existe um número não conhecido de abrigos que escapam totalmente à malha das autoridades competentes onde seres humanos e não-humanos vítimas de negligência e maus-tratos coexistem em permanência. Todos carecem de ajuda. Não sendo os proprietários dos abrigos portadores de DAA, estes precisam de apoio que vai desde os programas de esterilização, à alimentação, à manutenção de infra-estruturas com o mínimo de qualidade até aos programas de adoção entre muitos outros. Quando os proprietários exibem esta perturbação mental, ainda que os animais lhes sejam retirados, apresentam uma possibilidade de recidiva que andará perto dos 100\%. Quanto aos não-humanos, mesmo após resgate, podem exibir sequelas físicas e comportamentais permanentes, o que impossibilitará a sua integração em contexto familiar e portanto em futuras adopções (DOZIER et al., 2019).

Os portadores de DAA podem ser vistos como indivíduos que cometem crimes de maus-tratos que são puníveis com pena de prisão. Os profissionais de saúde mental devem estar alerta para esta realidade bem como as próprias autoridades e organizações de defesa dos animais. Alguns já defendem que se trata de uma psicopatologia própria não só devido às diferenças com os acumuladores de objectos mas também porque a medicação que lhes é dada não parece ter efeito nos indivíduos portadores de DAA (PRICE, 2017).

Encontrar o equilíbrio entre punir ou tratar os indivíduos que exibem DAA será sempre difícil para quem tem o poder de decisão e provavelmente obrigará a uma mudança do ponto de vista jurídico uma vez que estamos perante uma desordem do foro psicopatológico. A deteção precoce desta perturbação mental será a melhor solução para todas as partes envolvidas: i) para os indivíduos portadores de DAA que podem vir a usufruir de tratamento adequado; ii) para a saúde pública, evitando o aparecimento de zoonoses adicionais e iii) para os animais não humanos que estariam a cargo dos portadores de DAA se a perturbação mental não fosse detectada atempadamente. Tratase de um problema complexo com várias frentes que implica desafios para saúde mental (é uma desordem psicológica só reconhecida na década passada), para os agentes da autoridade, para os profissionais de bem-estar animal (LOCKWOOD, 2018) e para os animais não humanos. 


\title{
CrIme or ANIMAL hoARDING DISORDER? THE ROLE OF SOCIAL NETWORKS UNDERSTANDING THE EVENTS OF SANTO TIRSO
}

\begin{abstract}
In the early hours of July 19 (2020) in Santo Tirso, Portugal, a forest fire hit two illegal companion animal shelters. Half a hundred died. Hundred and ten nonhumans were rescued alive. The information conveyed by the media potentially suggests an animal hoarding case. Based on the Facebook posts of two of the largest Portuguese organizations standing for animal rights related to the incident, we tried to understand how they and their followers reacted to the event. The analysis was done based on content analysis techniques. The results suggest that both the organizations concerned and their followers perceived the event as a criminal act. Despite the available information, the possibility of an animal hoarding case was never mentioned in the posts on the analyzed pages or in the comments of their followers..
\end{abstract}

KEYWORDS: Animal hoarding disorder. Santo Tirso. Content analysis. Social networks. Animal rights

\section{¿CRImen o trastorno de aCumulación animal? El papel DE LAS REDES SOCIALES EN LA COMPRENSIÓN DE LOS HECHOS DE SANTO TIRSO}

RESUMEN: En la madrugada del 19 de julio (2020), en Santo Tirso (Portugal), un incendio forestal azotó dos refugios ilegales de animales de compañía. Medio centenar murieron. 110 no humanos fueron rescatados vivos. La información transmitida por los medios indica la posibilidad de que estemos ante un caso de acumulación de animales. Basándonos en las publicaciones en Facebook relacionadas con el incidente de dos de las mayores organizaciones portuguesas que defienden la causa animal, intentamos entender cómo reaccionaron ellos y sus seguidores ante el evento. El análisis se realizó con base en la técnica de análisis de contenido. Los resultados sugieren que tanto las organizaciones interesadas como sus seguidores percibieron el hecho como un acto delictivo. A pesar de la información disponible, la posibilidad de que estemos ante del "trastorno de acumulación animal" nunca se ha mencionado en las publicaciones de los murales analizados y sólo aparece una vez en el comentario de uno de sus seguidores.

PALABRAS CLAVE: Trastorno de acumulación de animales. Santo Tirso. Análisis de 
contenido. Redes sociales. Derechos de los animales.

\section{REFERÊNCIAS}

ARLUKE, Arnold; PATRONEK Garry; LOCKWOOD, Randall; CARDONA Allison. Animal Hoarding. In: MAHER, Jennifer; PIERPOINT Harriet; BEIRNE Piers (org.). The Palgrave International Handbook of Animal Abuse Studies. DOI 10.1057/978-1-137-43183-7_6., 2017.

ARLUKE, Arnold; FROST Randy; STEKETEE Gail; PATRONEK, Garry; LUKE, Carter; MESSNER, Edward; NATHANSON, Jane; PAPAZIAN, Michelle. Press Reports of Animal Hoarding. Society and Animals, n.10, v.2, p 113-135, jul. 2002.

ARLUKE, Arnold; SANDERS, Clinfton. Regarding Animals. Filadélfia: Temple University Press, 1996.

BARDIN, Laurence. Análise de Conteúdo. Lisboa: Edições 70, 2009.

BECK, Allan; KATCHER, Aaron. Between Pets and People - The Importance of Animal Companionship. West Lafayette: Purdue University Press, 1996.

BERRY, Colin; PATRONEK, Garry; LOCKWOOD Randall. Long-Term Outcomes in Animal Hoarding Cases. Animal Law, n. 11, v. 167, p167-194, jan. 2005.

BIRKE, Lynda; PARISI, Luciana. Animals, Becoming. In: STEEVES, H. Peter (org.). Animal Others: On Ethics, Ontology and Animal Life. Nova Iorque: State University of New York Press, 1999.

DIÁRIO DA RÉPÚBLICA. Decreto-Lei n. 116/98. Diário da Répública - I Série A 103. 5 mai. 1998.

DGAV - Direcção Geral de Agricultura e Veterinária. Disponível em: http://www.dgv.minagricultura.pt/portal/page/portal/DGV. Acesso em: 06 ago. 2020.

DOZIER, Mary E.; BRATIOTIS Christiana; BROADNAX Dominique; LE, Jenny; AYERS Catherine R. A description of 17 animal hoarding case files from animal control and a humane society. Psychiatry Research, n. 272, p.365-368, fev. 2019.

FERREIRA, Elisa Arrienti; PALOSKI Luís Henrique; COSTA, Dalton Breno; FIAMETTI Vânia Saretta; OLIVEIRA, Camila Rosa de; ARGIMON, Irani Iracema de Lima; GONZATTI Valéria; IRIGARAY Tatiana Quarti. Animal Hoarding Disorder: A new psychopathology? 
Psychiatry Research. Volume 258, December 2017, p.221-225. Disponível em: http://dx.doi.org/10.1016/j.psychres.2017.08.030. Acesso em: 26 out. 2020.

FRANKLIN, Adrian. Animals and Modern Cultures - A Sociology of Human-Animal Relations in Modernity. Londres: Sage Publications, 1999.

KOZINETS, Robert V. Netnography: Redefined. Londres: Sage Publication, 2015.

LEACH, Edmund. Anthropological aspects of language: animal categories and verbal abuse. In: LENNEBERG, Eric .H. (org.). New Directions in the Study of Language. Cambridge: MIT Press, 1964.

LOCKWOOD, Randall. Animal hoarding: The challenge for mental health, law enforcement, and animal welfare professionals. Behavioral Sciences \& the Law, 1-19. https://doi.org/10.1002/bsl.2373. 2018.

NOTÍCIAS AO MINUTO. No meio da tragédia, um final feliz: Homem encontra cão perdido há 2 anos. Publicado em 20 julho de 2020. Disponível em:

https://www.noticiasaominuto.com/pais/1534155/no-meio-da-tragedia-um-final-feliz-homemencontra-cao-perdido-ha-2-anos. Acesso em: 17 ago. 2020.

OCKENDEN, Emma M; DE GROEF, Bert; MARSTON, L. Animal Hoarding in Victoria, Australia: An Exploratory Study. Anthrozoös, Vol. 27, n. 1, p.33-47. 2014

PATRONECK, Garry, J. The Hoarding of Animals: An Update. Psychiatric Times, 30 April, 2015. https://www.psychiatrictimes.com/view/hoarding-animals-update. Acesso em 23 de Setembro de 2020.

PATRONECK, Garry, J. Animal hoarding: its roots and recognition. DVM360. Agosto 1, 2006. https://www.dvm360.com/view/animal-hoarding-its-roots-and-recognition. Acesso em 23 de Setembro de 2020.

PATRONECK, Garry J. Hoarding of animals: an under-recognized public health problem in a difficult-to-study population. Public Health Reports, n. 14, v. 1, p 81-87, fev. 1999.

PEREIRA, Miguel. Animais com lixo não é crime: Porque foi arquivada queixa contra abrigos para animais em Santo Tirso. Diário de Notícias. 19 jul. 2020. Disponível em: https://www.dn.pt/pais/animais-com-lixo-nao-e-crime-porque-foi-arquivada-queixa-contraabrigos-para-animais-em-santo-tirso-12440915.html. Acesso em 5 ago. 2020.

PRICE, Michael. Animal hoarding is its own mental disorder, study argues. Science, 18 Set. 2017. Disponível em https:/www.sciencemag.org/news/2017/09/animal-hoarding-its-ownmental-disorder-study-argues. Acesso em 26 de Set. 2020. 
SANDERS, Clinfton. Understanding Dogs: Living and Working with Canine Companions. Filadélfia: Temple University Press, 1999.

UNG, Jennifer E; DOZIER, Mary E; BRATIOTIS, Christiana; AYERS, Catherine R. An Exploratory Investigation of Animal Hoarding Symptoms in a Sample of Adults Diagnosed With Hoarding Disorder. Journal of Clinical Psychology, vol. 73, n. 9, p.1114-1125. 2017.

VARIS, Pila. Digital Ethnography. In: GEORGAKOPOULOU, Alexandra and SPILIOTI, Tereza (org.) The Routledge Handbook of Language and Digital Communication, Londres: Routledge, 2016. p. 55-68.

Recebido em 19/08/2020.

Aprovado em 26/08/2020. 